\title{
OBSERVATIONS
}

\section{Tranexamic acid in trauma: we need stronger global health policy}

Tranexamic acid substantially reduces death in bleeding trauma patients. So why are the World Health Organization, the United Nations, the World Bank, and Unicef not ensuring global implementation, ask lan Roberts and colleagues

José Caballero Alvarado Hospital Regional Docente de Trujillo, Peru, Yashbir Dewan MIND-Max Institute of Neurosciences Dehradun, India, Hesham Fathy Elsayed, Suez Canal University Hospital, Egypt, Tamar Gogichaishvili High Technology Medical Centre, Georgia, Sanjay Gupta Fortis Hospital Delhi, India, B J Hunt Guy's and St Thomas' NHS Foundation Trust, UK, Pius Iribhogbe University of Benin Teaching Hospital, Nigeria, Mario Izurieta Hospital Alcivar, Ecuador, Hussein Khamis Mataria Teaching Hospital, Egypt, Edward O Komolafe Obafemi Awolowo University Teaching Hospital, Nigeria, Jorge H Mejía Mantilla Fundación Valle del Lili, Colombia, Jaime Miranda Universidad Peruana Cayetano Heredia, Peru, Carlos H Morales Uribe Hospital Universitário San Vicente Fundación, Colombia, Oluwole Olaomi National Hospital Abuja, Nigeria, Fatos Olldashi University Hospital of Trauma, Albania, Pablo Perel London School of Hygiene and Tropical Medicine, UK, P V Ramana Care Neurosciences and Trauma Centre, India, R R Ravi, Medical Trust Hospital Kochi, India, Ian Roberts London School of Hygiene and Tropical Medicine, UK, Haleema Shakur London School of Hygiene and Tropical Medicine, UK

\begin{abstract}
You might expect that the identification of a highly cost effective treatment for a disease that kills more people each year than HIV/AIDS, malaria, and tuberculosis combined would stimulate an immediate global health policy response, with strong efforts to make the treatment freely available to all those who need it. ${ }^{1}$ Knowing that the United Nations General Assembly had proclaimed 2011-20 to be a "decade of action" for tackling this particular health scourge, you might feel sure that concerted action was being taken. ${ }^{2}$ You would be wrong. The "disease" is trauma, and the treatment is a short infusion of a generic drug called tranexamic acid, but there has been no global health policy response..$^{3-6}$

In 2010 a collaboration of doctors and nurses from 40 countries reported that tranexamic acid safely reduces mortality in bleeding trauma patients. Given within three hours of injury, it reduced the risk of bleeding to death by one third, with no discernible side effects. ${ }^{4}$ Economic analysis shows that tranexamic acid in trauma is among the most cost effective ways available to save a life-more cost effective than antiretroviral treatment for HIV and nearly as cost effective as bed nets for malaria prevention. ${ }^{5}$ If all patients admitted to hospital with traumatic bleeding worldwide received tranexamic acid within three hours, there would be at least 100000 fewer trauma deaths a year. ${ }^{7}$
\end{abstract}

Within weeks of publication of these findings, the British army was using tranexamic acid on the battlefield, and two years later it has been widely implemented throughout the NHS, having been included in the guidelines of the Joint Royal Colleges Ambulance Liaison Committee for prehospital practice and in the Department of Health's best practice for trauma. ${ }^{8}$ The trial investigators successfully applied to get tranexamic acid included in the World Health Organization's list of essential medicines, but implementation efforts by organisations from which we would expect health policy leadership-WHO, the UN, World Bank, and Unicef-have been limp or absent.

It seems that some deaths are more important than others. In 2011 more than eight million people with HIV infection in low and middle income countries received antiretroviral treatment. ${ }^{9}$ This is appropriately considered one of the most important global health achievements of the past decade and is all the more remarkable because diagnosis of HIV infection requires a laboratory test and the patient must be treated for life. But if such patients arrive at the emergency department with major trauma (and about a quarter of trauma patients in sub-Saharan Africa are HIV positive) they might die for want of a short infusion of a drug that costs a fraction of the cost of a unit of blood. ${ }^{10}$

Wider use of tranexamic acid in surgery would save blood. A systematic review of randomised trials showed that tranexamic 
acid reduced the number of patients receiving a blood transfusion by a third. ${ }^{11}$ Reducing use of blood in surgery would make more available for situations where transfusion might be life saving, such as in children with malaria or mothers with postpartum bleeding.

And tranexamic acid is safer than blood. The risks of becoming infected with HIV, hepatitis B virus, or hepatitis C from a blood transfusion in sub-Saharan Africa are estimated at 1, 4.3, and 2.5 infections per 1000 units, respectively. ${ }^{12}$ If annual transfusion requirements projected by $\mathrm{WHO}$ were met, blood transfusions alone would be responsible for 28595 hepatitis B infections, 16625 hepatitis $\mathrm{C}$ infections, and $6650 \mathrm{HIV}$ infections every year. Because it reduces the need for transfusion, tranexamic acid is a cost effective way to reduce viral infections transmitted by transfusion. ${ }^{13}$

Recognising these opportunities requires a new mode of thinking. It requires a move away from disease based leadership, where tribal leaders bang the drum of disease burden in search of the funds to prevent the specific illness that interests them most, towards people centred care, aimed at achieving the best health given the available resources.

The CRASH-2 trial was funded by UK taxpayers, and UK taxpayers have been the first to benefit. However, the trial was possible only because hundreds of doctors and nurses in 40 countries worked together in the interests of patients everywhere to recruit the 20211 patients, 3076 of whom died. The trial turned private tragedy into a public good, and this must now be used to inform global policy.
Competing interests: We have read and understood the BMJ Group policy on declaration of interests and have no relevant interests to declare.

Provenance and peer review: Not commissioned; not externally peer reviewed.

1 Lozano R, Naghavi M, Foreman K, Lim S, Shibuya K, Aboyans V, et al. Global and regional mortality from 235 causes of death for 20 age groups in 1990 and 2010: a systematic analysis for the Global Burden of Disease Study 2010. Lancet 2012;380:2095-128.

2 Road Safety Fund. UN decade of action for road safety. www.roadsafetyfund.org/ TagSymbol/Pages/default.aspx.

3 CRASH-2 Collaborators. Effects of tranexamic acid on death, vascular occlusive events, and blood transfusion in trauma patients with significant haemorrhage (CRASH-2): a randomised, placebo-controlled trial. Lancet 2010;376:23-32.

4 CRASH-2 collaborators. Importance of early treatment with tranexamic acid in bleeding trauma patients: exploratory analysis of the CRASH-2 trial. Lancet 2011;377:1096-101.

5 Roberts I, Perel P, Prieto-Merino D, Shakur H, Coats T, Hunt BJ, et al. Effect of tranexamic acid on mortality in patients with traumatic bleeding: prespecified analysis of data from randomised controlled trial. BMJ 2012;345:e5839.

6 Guerriero C, Cairns J, Perel P, Shakur H, Roberts I. Cost-effectiveness analysis of administering tranexamic acid to bleeding trauma patients using evidence from the CRASH-2 trial. PLOS One 2011;6:e18987.

7 Ker K, Kiriya J, Perel P, Edwards P, Shakur H, Roberts I. Avoidable mortality from giving tranexamic acid to bleeding trauma patients: an estimation based on WHO mortality data, a systematic literature review and data from the CRASH-2 trial. BMC Emerg Med 2012;12:3.

8 Injured soldiers in Afghanistan saved by blood-clotting drug, 19 Jan 2011. www.youtube. com/watch?v=0j6P2cwwRYw.

9 Sidibé M, Piot P, Dybul M. Aids is not over. Lancet 2012;380:2058-60.

10 Sefeane TI, Lukhele M, Ramokgopa MT. Seroprevalence of HIV in the acute orthopaedic trauma at the Charlotte Maxeke Johannesburg Academic Hospital. S A Orthopaed J 2011;10:30-3.

11 Ker K, Edwards P, Perel P, Shakur H, Roberts I. Effect of tranexamic acid on surgical bleeding: systematic review and cumulative meta-analysis. BMJ 2012;344:e3054.

12 Jayaraman S, Chalabi Z, Perel P, Guerriero C, Roberts I. The risk of transfusion-transmitted infections in sub-Saharan Africa. Transfusion 2010;50:433-42.

13 Guerriero C, Cairns J, Jayaraman S, Roberts I, Perel P, Shakur H. Giving tranexamic acid to reduce surgical bleeding in sub-Saharan Africa: an economic evaluation. Cost Eff Resour Alloc 2010;8:1.

Cite this as: BMJ 2013;347:f4593

๑) BMJ Publishing Group Ltd 2013 